\title{
Incubation qualities of the eggs of the laying hens of the parent herd when using probiotics in the diet
}

\author{
Alexander Ovchinnikov ${ }^{1 *}$, Lyudmila Ovchinnikov², Yulia Matrosov $^{3}$, Dmitry Bryukhanov ${ }^{3}$ \\ and Alexei Belookov ${ }^{1}$ \\ ${ }^{1}$ South Ural state agrarian university, Department of Feeding, animal hygiene, technology of production \\ and processing of agricultural products, 457100, Gagarin St., 13, Troitsk, Chelyabinsk region, Russia \\ ${ }^{2}$ South Ural state agrarian university, Department of Biology, ecology, genetics and animal breeding, \\ 457100, Gagarin St., 13, Troitsk, Chelyabinsk region, Russia \\ ${ }^{3}$ South Ural state agrarian university, Department of animal Husbandry and poultry farming, 457100, \\ Gagarin St., 13, Troitsk, Chelyabinsk region, Russia
}

\begin{abstract}
Occasional use of the probiotics Levisel SB Plus and Tsellobacterin $-\mathrm{T}$ in a dose $0.50 \mathrm{~kg} / \mathrm{t}$ of the mixed fodder in a diet of the laying hens at the age 21-26, 34-39 и 45-48 weeks has increased metabolic processes in the body of a bird and productivity of the laying hens in a group with Levisel SB Plus by $10.6 \%$, with a dash Tsellobacterin - T - by $16.1 \%$, but it did not affect the weight of the egg during all periods of the productive cycle. The egg incubation results showed that probiotice Levisel SB Plus increased egg hatability by $4.1 \%$, Tsellobacterin-T by $6.2 \%$, their fertilization by 2.1 and $4.2 \%$, the withdrawal of young chickens by $3.5 \%$ and $5.1 \%$. The addition of probiotics did not change the hatchability of eggs (93.22 and 93.17\%) in these groups, but reduced the amount of unfertilized eggs by 1.8 and $10.3 \%$. There was a higher content of carotenoids and vitamin A in the eggs of the laying hens and in the body of daily chickens.

Using the probiotics in the diet of laying hens of the parent herd has reduced the cost of feeding for 10 eggs by $8.2-8.5 \%$, with a dash of Levisel SB Plus by $15,0-15,4 \%$, with a dash of

Tsellobacterin $-\mathrm{T}$ to the weight of the egg by $1,8-9,7 \%$ and $15.3-15.5 \%$ respectively. At the same time, the payment of food products increased in the group using Levisel SB Plus by 10.3-10.7\%, with Tsellobacterine - T by 20.9$21.7 \%$, the profitability of production increased by 13.1 and $22.3 \%$.
\end{abstract}

\section{Introduction}

Probiotic fodder additives used in the diets of agricultural animals and birds instead of antibiotics, have a polyfunctional effect on the body of the bird. Daily using there was their unreasonable cost and an additional bacterial load on the intestinal normoflora, while the periodic application of the fodder additive probiotics the most tense period of layding eggs, the peak productivity and reduction can have a prolonged effect on metabolic processes in

\footnotetext{
${ }^{*}$ Corresponding author: ovchin@bk.ru
} 
the body, immune protection, productivity and reduce the extraction of poultry of the laying hens for diseases of infectious etiology.

Therefore, the purpose of the research was to compare the incubation qualities of the egg of the laying hens of the parent herd of the meat direction of productivity and their quality with the periodic using of probiotics in the diet.

Initially, probiotics were used in the treatment and prevention of gastrointestinal diseases of agricultural animals, in the following as a biologically active additives, normalizing bacterial composition of the intestine [3,8], increasing variability and nutrient use of the diet, safety of the livestock [2], immune status of an organism [1]. The variety of bacterial cultures allowed to obtain different results in the scientific research. So, inclusion of the sinbiotics "ProStor" in the amount of $0.50 \mathrm{~kg} / \mathrm{t}$ of mixed fodder in the diet of the growing birds of the meat direction, did not give reliable differences in living weight at the time of the transfer of the bird to the parent herd, but the safety of the head of the experimental group was higher by $2.6 \%$, which amounted to a profit of $2.7 \%$. At the same time I.A. Egorov and others [4] noted that spore forms of probiotics reduce lipolitical, but increase activity of duodenal himus.

In research of the A.M. Mardanova and others [6] was proved that different strains of the same culture can have a different effect on the growth and development of the bird. In particular, they established that the strain Bac.GM 2 and GM5 in concentration of $1 \times 107$ $\mathrm{KOE}$ in irrigation of mixed fodder of the bird increased the living mass of broilers at reaching 40 days by 2.2 and $8.6 \%$, which was the reason to recommend a strain of Bac. GM 5 for further research in poultry farming. Using of the probiotic Levisel SB Plus at a dose of 1.0 $\mathrm{kg} / \mathrm{t}$ of mixed fodder, according to N.M. Samokhina and other [7], allowed to increase the uniformity of the herd by $10-15 \%$, egg productivity of chickens - by $3.0-4.0 \%$, the output of the incubation egg - by $1.5 \%$, reduce the egg's retreat due to notch and broken- by $0.8-1.2 \%$.

Probiotics from the group Bac.Subtilis, unlike lacto- and bifidobacteria, have a prolonged effect, which largely depends on the concentration of bacterial cultures. So, in the testing of probiotic Vetosporin-active in the diet of meat chickens of the parent cross herd "Ross-308" aged from 20 to 60 weeks, in a dose from 0.06 to $0.15 \%$ of the mass of mixed fodder, established an increase in egg productivity in 40 -week age with a dose of $0.09 \%$ by $0.8 \%$, in 50 -week - by $14.7 \%$. Higher doses did not have a positive effect on egg productivity. The hens of experimental groups of maximum egg-laying reached 7-10 days before the control group.

The different composition of probiotics does not effect on metabolism in organism of an agricultural bird equally. Thus, feeding of the broilers geese of the probiotic Vitafort with spore concentration 109 COE g-1 0.05 g per $10 \mathrm{~kg}$ of live weight and Lactobifadol in the amount of $0.2 \mathrm{~g} \mathrm{~kg}-1$ of body weight, it was noted that for 20 days the protein metabolism of experimental groups was higher than the control for 26.7 and $27.9 \%$, in 30-day - by 21.2 and $12.6 \%$, at the age of 62 days - by 9.7 and $15.1 \%$, respectively. Differences in carbohydrate metabolism were recorded in testing birds 30-day age, which was accompanied by an increase in blood glucose levels by 24.7 and $12.3 \%$ and their further predominance over the control group until the end of the feeding. It is characteristic that Vitaport from the age of 10day geese increased the metabolism of calcium and phosphorus in organism, while Lactobifadol only from 20 days [5]. The greatest biological effect from the using of probiotics is noted when they are used with other biologically active additives (antioxidants, microelements, enterosorbents with different crystalline lattice).

\section{Materials and methods}

The research was carried out at the poultry factory of LLC 'Ravis-poultry factory Sosnovskaya' of the Chelyabinsk region, on the tribal reproductive of the II-th order 
"Peschannoe department". The livestock of the I control and experimental groups were formed by the repair young of the cross 'ISAHubbarf - 15', which during the growing period at the age of the first 6 weeks received probiotics Levisel SB Plus (II experimental group) and Tsellobacterin-T (III experimental group) in a dose of $0.50 \mathrm{~kg} \mathrm{t}-1$ of mixed fodder. Laying hens of II and III experimental group, 100 heads in each, were under the same conditions of maintenance and feeding, received probiotics in the same dose at the age of 21 26, 34-39 and 45-48 weeks, that is, before the beginning of the peak productivity, at its onset and completion. Egg production of chickens was taken into account every day for each group. The incubation qualities of the egg were characterized by fertilization ability, withdrawal, hatching - by egg defects. Metabolism processes in the organism of laying hens were studied at the age of 29 and 44 weeks with 5 heads from each group. The physico-biochemical parameters of eggs were determined in an egg of medium size according to generally accepted methods, followed by the study of the biochemical composition of the organisms of daily chickens.

Economic efficiency was calculated on the produced costs of feed, food payment and profitability of production. The obtained material was treated biometrically with the determination of the level of reliability.

\section{Results and discussion}

For the productive cycle, the livestock of laying hens received a full-length mixed fodder of the PC-1 recipe.

At the same time, the average daily consumption of full-length mixed fodder by the bird of control and experienced groups was controlled in accordance with their living mass and the level of egg productivity. Thus, at the age of 21-35 weeks was 137.0-147.42 g, 35-50 weeks - 137.67-151.59 g, 51-55 weeks - 140.69-151.54 g. The live weight of the bird was taken into account by monthly weighing.

The analysis of egg laying of hens during the productive period showed (table 1) that in the bird receiving probiotics it was reliably above the control group from the age of 26 weeks by a value of $16.5 \%$ in II $(\mathrm{P} \leq 0.05)$ and by $15.8 \%$ - in the III experimental group $(\mathrm{P} \leq 0.05)$.

Table 1. Egg productivity per average ear, pieces $\left(X \pm m_{x}, n=100\right)$

\begin{tabular}{|l|c|c|c|}
\hline \multirow{2}{*}{ Age, week } & \multicolumn{3}{|c|}{ Group } \\
\cline { 2 - 4 } & I & II & III \\
\hline $21-25$ & $1.28 \pm 0.38$ & $2.52 \pm 0.75$ & $1.81 \pm 0.54$ \\
\hline $26-29$ & $18.71 \pm 0.89$ & $21.80 \pm 0.53^{*}$ & $21.67 \pm 0.81^{*}$ \\
\hline $30-33$ & $23.09 \pm 0.05$ & $23.71 \pm 0.06^{* * *}$ & $24.83 \pm 0.06^{* * *}$ \\
\hline $34-37$ & $22.25 \pm 0.09$ & $23.41 \pm 0.05^{* * *}$ & $24.03 \pm 0.08^{* * *}$ \\
\hline $38-41$ & $20.85 \pm 0.12$ & $22.40 \pm 0.13^{* * *}$ & $22.75 \pm 0.08^{* * *}$ \\
\hline $42-45$ & $19.02 \pm 0.11$ & $20.93 \pm 0.12^{* * *}$ & $20.96 \pm 0.13^{* * *}$ \\
\hline $46-49$ & $16.39 \pm 0.17$ & $19.15 \pm 0.15^{* * *}$ & $19.25 \pm 0.09^{* * *}$ \\
\hline $50-53$ & $13.93 \pm 0.14$ & $16.81 \pm 0.17^{* * *}$ & $17.62 \pm 0.12^{* * *}$ \\
\hline $54-54,6$ & $5.19 \pm 0.57$ & $4.84 \pm 1.10$ & $10.31 \pm 0.99^{* * *}$ \\
\hline On average & $15.63 \pm 2.54$ & $17.29 \pm 2.68$ & $18.14 \pm 2.50$ \\
\hline
\end{tabular}

Hereinafter: *) $P \leq 0.05 ; * *) P \leq 0.01 ; * * *) P \leq 0.001$.

In the peak of bird productivity (30-33 weeks.), the difference between control and experimental groups was $2.3 \%$ (II experimental, $\mathrm{P} \leq 0.001$ ) and $7.5 \%$ (III experimental group, $\mathrm{P} \leq 0.001)$. This regularity was preserved in subsequent periods of egg laying. At the age of hens $42-45$ weeks it was respectively higher by 10.0 and $10.2 \%(\mathrm{P} \leq 0.001), 50-53$ weeks - 
20.7 and $26.5 \%(\mathrm{P} \leq 0.001)$, by the completion of the egg laying of the tone was higher only in the bird of the III experimental group $(\mathrm{P} \leq 0.001)$.

On average, for the whole accounting period, the egg productivity of hens of the I control group was 15.63 eggs, in II experimental group - 10.6\%, in the III experimental group - by $16.1 \%$.

The productivity of the bird is largely connected with the metabolism in its organism, the intensity of which is affected by biologically active feed additives, which are part of the mixed fodder. Periodic research of the blood of hens for the content of metabolites of metabolism in it (Table 2) showed that the bird of the experimental groups it was higher in comparison with the control group.

Table 2. The biochemical composition of blood of an adult bird $\left(X \pm m_{x}, n=5\right)$

\begin{tabular}{|c|c|c|c|}
\hline \multirow{2}{*}{ Indicator } & \multicolumn{3}{|c|}{ Group } \\
\hline & $\mathrm{I}$ & II & III \\
\hline & \multicolumn{3}{|c|}{29 weeks } \\
\hline General protein , $\mathrm{g} \mathrm{l}^{-1}$ & $54.40 \pm 5.44$ & $56.80 \pm 2.94$ & $57.32 \pm 3.95$ \\
\hline Urea, $\mathrm{mmol} \mathrm{l}^{-1}$ & $2.53 \pm 0.08$ & $2.32 \pm 0.14$ & $2.23 \pm 0.07^{*}$ \\
\hline General lipids, $\mathrm{g} \mathrm{l}^{-1}$ & $9.00 \pm 0.92$ & $9.95 \pm 0.32$ & $9.80 \pm 0.58$ \\
\hline Beta-lipoproteins, mg \% & $720.29 \pm 50.00$ & $793.80 \pm 55.92$ & $822.92 \pm 32.65$ \\
\hline Glucose, $\mathrm{mmol} \mathrm{l}^{-1}$ & $11.40 \pm 0.18$ & $11.48 \pm 0.33$ & $11.40 \pm 0.15$ \\
\hline AsAt, $\mathrm{mmol} \mathrm{l}^{-1} \mathrm{~h}$ & $2.38 \pm 0.03$ & $2.42 \pm 0.04$ & $2.44 \pm 0.03$ \\
\hline $\mathrm{AlAT}, \mathrm{mmol} \mathrm{l}^{-1} \mathrm{~h}$ & $0.36 \pm 0.07$ & $0.35 \pm 0.03$ & $0.36 \pm 0.05$ \\
\hline Calcium, mmol l-1 & $4.62 \pm 0.06$ & $4.99 \pm 0.06^{*}$ & $5.16 \pm 0.06 * * *$ \\
\hline \multirow[t]{2}{*}{ Phosphorus, mmol l-1 } & $2.51 \pm 0.05$ & $2.78 \pm 0.05^{*}$ & $2.71 \pm 0.04$ \\
\hline & \multicolumn{3}{|c|}{44 weeks } \\
\hline General protein, $\mathrm{g} \mathrm{l}^{-1}$ & $61.40 \pm 3.02$ & $64.84 \pm 2.47$ & $67.28 \pm 2.28$ \\
\hline Urea, mmol l-1 & $4.71 \pm 0.14$ & $4.26 \pm 0.11 *$ & $4.09 \pm 0.05 * *$ \\
\hline General lipids, $\mathrm{g} \mathrm{l}^{-1}$ & $7.14 \pm 0.62$ & $7.83 \pm 0.38$ & $8.18 \pm 0.33$ \\
\hline Beta-lipoproteins, mg \% & $696.52 \pm 48.48$ & $758.02 \pm 34.17$ & $774.80 \pm 29.74$ \\
\hline Glucose, $\mathrm{mmol} \mathrm{l}^{-1}$ & $11.44 \pm 0.08$ & $11.60 \pm 0.10$ & $11.63 \pm 0.21$ \\
\hline AsAt, $\mathrm{mmol} \mathrm{l}^{-1} \mathrm{~h}$ & $2.60 \pm 0.08$ & $2.91 \pm 0.13$ & $3.07 \pm 0.08 * * *$ \\
\hline AlAT, $\mathrm{mmol} \mathrm{l}^{-1} \mathrm{~h}$ & $0.37 \pm 0.03$ & $0.49 \pm 0.07$ & $0.51 \pm 0.07$ \\
\hline Calcium, mmol l-1 & $5.19 \pm 0.08$ & $5.73 \pm 0.07 * * *$ & $5.92 \pm 0.06 * * *$ \\
\hline Phosphorus, mmol l-1 & $2.70 \pm 0.14$ & $2.89 \pm 0.12$ & $2.97 \pm 0.12$ \\
\hline
\end{tabular}

Thus, at the age of 29 weeks, with the same blood content of birds of all groups of the general protein, the urea level of the II test group of hens decreased by $8.3 \%$, in the III group - by $11.9 \%$ compared to the I control group, which had a level of $2.53 \mathrm{mmol} / 1$. Similar positive changes were observed in lipid metabolism; the total content of lipids in experimental groups increased by $8.9-10.6 \%$, beta-lipoproteins by $10.2-14.2 \%$. Due to increase the egg-laying of hens of experimental groups in their blood was increase in the level of calcium by $8.0-11.7 \%(\mathrm{P} \leq 0.05-0.001)$ and phosphorus - by $8.0-10.8 \%(\mathrm{P} \leq 0.05)$ was noted.

Restudy birds at the age of 44 weeks showed that a change in the rate of hens feeding in their blood resulted in an increase in the level of total protein and a decrease in the level of total lipids. However, judging by the amount of urea, the use of nitrogenous feed substances in poultry of the experimental groups was higher than the control group by $9.6 \%$ in the $\mathrm{II}(\mathrm{P} \leq 0.05)$ and by $13.2 \%$ in the III experimental group $(\mathrm{P} \leq 0.01)$, and beta - lipoproteins-by 8.8 and $11.2 \%$. At this age, the functional activity of the liver of III poultry group was higher than the control I group by $18.1 \%$ (P0.001), and II group by $11.9 \%$. The concentration of 
calcium in the blood of hens of experimental groups exceeded the analogueues of the control group by $10.4-14.1 \%(\mathrm{P} \leq 0.001)$, phosphorus - by $7.0-10.0 \%$.

If changes in egg production were observed under the influence of probiotics, there were no significant differences in egg mass between the control and experimental groups (table 3 ).

Table 3. Egg weight of laying hens, $g\left(X \pm m_{x}, n=30\right)$

\begin{tabular}{|l|c|c|c|}
\hline \multirow{2}{*}{ Age, week } & \multicolumn{3}{|c|}{ Group } \\
\cline { 2 - 4 } & I & II & III \\
\hline $21-25$ & $45.37 \pm 0.21$ & $45.92 \pm 0.15$ & $46.16 \pm 0.30$ \\
\hline $26-29$ & $52.78 \pm 1.14$ & $52.38 \pm 1.14$ & $52.35 \pm 1.46$ \\
\hline $30-33$ & $57.58 \pm 0.55$ & $56.68 \pm 0.71$ & $57.65 \pm 0.53$ \\
\hline $34-37$ & $59.16 \pm 0.27$ & $60.11 \pm 0.53$ & $59.44 \pm 0.23$ \\
\hline $38-41$ & $61.87 \pm 0.56$ & $62.97 \pm 0.31$ & $61.87 \pm 0.41$ \\
\hline $42-45$ & $64.12 \pm 0.21$ & $64.56 \pm 0.22$ & $64.37 \pm 0.39$ \\
\hline $46-49$ & $65.58 \pm 0.20$ & $65.74 \pm 0.09$ & $66.13 \pm 0.24$ \\
\hline $50-53$ & $66.20 \pm 0.18$ & $66.59 \pm 0.17$ & $66.46 \pm 0.09$ \\
\hline $54-54.6$ & $66.67 \pm 0.15$ & $67.25 \pm 0.11$ & $67.05 \pm 0.16$ \\
\hline
\end{tabular}

During the scientific and economic experiment, the quality of the incubation egg of different productive periods of poultry was studied: small, medium and large eggs. However, for breeding purposes, only a medium-sized egg is used for incubation, its qualitative characteristics are shown in table 4.

Table 4. Results of egg incubation in egg-laying of hens aged 31-34 weeks $\left(X \pm m_{x}, n=8\right)$

\begin{tabular}{|l|c|c|c|}
\hline \multirow{2}{*}{ Indicator } & \multicolumn{3}{|c|}{ Group } \\
\cline { 2 - 4 } & I & II & III \\
\hline Laid eggs for incubation, PCs & 300 & 300 & 300 \\
\hline Egg weight, g & $61.1 \pm 0.24$ & $61.9 \pm 0.23$ & $62.1 \pm 0.21$ \\
\hline Egg fertilization, \% & $89.7 \pm 0.62$ & $91.9 \pm 0.48$ & $93.9 \pm 0.29^{* * *}$ \\
\hline Hatched of chickens, heads & $246.59 \pm 3.82$ & $256.78 \pm 1.52$ & $261.83 \pm 1.68^{* *}$ \\
\hline Hatchability of eggs, \% & $91.62 \pm 0.79$ & $93.21 \pm 0.77$ & $93.17 \pm 0.73$ \\
\hline Breeding of young animals, \% & $82.2 \pm 1.27$ & $85.7 \pm 0.51$ & $87.3 \pm 0.56^{* *}$ \\
\hline Incubation waste: & & & \\
\hline not fertilized, PCs & $30.9 \pm 1.85$ & $24.23 \pm 1.43$ & $18.15 \pm 0.86$ \\
\hline$\%$ & 57.9 & 56.1 & 47.6 \\
\hline False fertilization, PCs & $6.45 \pm 2.11$ & $5.55 \pm 1.25$ & $4.95 \pm 1.70$ \\
\hline$\%$ & 12.1 & 12.8 & 13.0 \\
\hline - blood-ring, PCs & $2.33 \pm 0.23$ & $3.08 \pm 0.71$ & $3.52 \pm 1.01$ \\
\hline$\%$ & 4.4 & 7.1 & 9.2 \\
\hline - rotten egg, PCs & - & $0.23 \pm 0.02$ & $0.75 \pm 0.50$ \\
\hline$\%$ & - & 0.5 & 2.0 \\
\hline frozen embryos, PCs & $9.08 \pm 1.24$ & $6.23 \pm 0.23$ & $6.22 \pm 0.43$ \\
\hline$\%$ & 17.0 & 14.4 & 16.3 \\
\hline - weaklings, PCs & $4.65 \pm 0.62$ & $3.90 \pm 1.38$ & $4.58 \pm 0.69$ \\
\hline$\%$ & 8.7 & 9.0 & 12.0 \\
\hline Total defects, PCs & $53.41 \pm 3.82$ & $43.22 \pm 1.65$ & $38.17 \pm 2.02$ \\
\hline$\%$ & 17.8 & 14.4 & 12.7 \\
\hline
\end{tabular}

The result show that in comparison with the I control group, the number of hatched chickens in the II experimental group was higher by 10.19 pieces, in the III experimental 
group-by 15.24 pieces $(\mathrm{P} \leq 0.01)$, or by 4.1 and $6.2 \%$, respectively, which made the egg fertilization at the level of $89.7 \%, 91.9$ and $93.95 \%(\mathrm{P} \leq 0.001)$. At the same time, the hatchability of eggs in the experimental groups was the same (93.22 and $93.17 \%)$, but exceeded the I control group by 1.59 and $1.55 \%$ due to a decrease amount of unfertilized eggs by 1.8 and $10.3 \%$. The output of young animals from the eggs of chickens in the experimental groups also exceeded the control group by $3.5 \%$ in the second group and $5.1 \%$ $(\mathrm{P} \leq 0.01)$ in the third experimental group. Feed additive of probiotics allowed to reduce incubation waste in group II by $3.4 \%$, in group III-by $5.1 \%$ due to unfertilized eggs, false fertilization, frozen embryos, weaklings. However, in these groups, there is an increase in such a defect as blood-ring and rotten eggs.

The viability of newborn chickens and their living weight largely depends on the content of nutrients in the incubation egg, which directly enter it from full-size mixed fodder. Therefore, the qualitative composition and concentration of nutrients in the dry substance of mixed fodder directly affect the viability of the future young animals. Giving that the average egg size is mainly used for incubation during the peak of egg productivity of hens, we took for analysis an egg from hens aged 34 weeks, average in size and weight. The data of the physico-biochemical parameters of the incubation egg are presented in table 5.

Table 5. Physical and biochemical parameters of an incubation egg $\left(X \pm m_{x}, n=6\right)$

\begin{tabular}{|c|c|c|c|}
\hline \multirow{2}{*}{ Indicator } & \multicolumn{3}{|c|}{ Group } \\
\hline & I & II & III \\
\hline Average egg weight, $g$ & $58.57 \pm 0.07$ & $59.79 \pm 0.18^{* * *}$ & $59.24 \pm 0.14 * * *$ \\
\hline Content in the yolk: & & & \\
\hline Vitamin A, mcg g ${ }^{-1}$ & $10.78 \pm 0.29$ & $11.66 \pm 0.98$ & $13.14 \pm 1.06$ \\
\hline Carotenoids, $\mathrm{mcg} \mathrm{g}^{-1}$ & $26.13 \pm 1.91$ & $24.65 \pm 1.38$ & $28.32 \pm 1.06$ \\
\hline Thickness of eggshell, $\mathrm{mm}$ & $0.35 \pm 0.001$ & $0.37 \pm 0.001$ & $0.35 \pm 0.01$ \\
\hline Acid number, mg KOH g ${ }^{-1}$ & $5.35 \pm 0.32$ & $5.24 \pm 0.29$ & $5.18 \pm 0.31$ \\
\hline Density, $\mathrm{g} \mathrm{dm}^{-1}$ & $1.08 \pm 0.001$ & $1.08 \pm 0.001$ & $1.08 \pm 0.001$ \\
\hline
\end{tabular}

The data obtained indicate that with the increase in the mass of the egg, there is a tendency to increase the content of vitamin A. Thus, in comparison with the I control group, its number in the III and III experimental group increased by 8.2 and $21.9 \%$, respectively, and carotenoids in the III group - by $8.4 \%$. At the same time, the thickness of the shell in the egg of all groups of birds was the same $(0.35-0.37 \mathrm{~mm})$, as well as the density, the value of which was $1.08 \mathrm{~g} \mathrm{dm} 3-1$. The acid number of chickens eggs of control and experimental groups corresponded to normative data and was in the range of 5.18-5.35 mg CON g-1.

The sufficiency of biologically active substances for the development of the embryo and the first days of postnatal development is evidenced by the data of the biochemical composition of the body of daily chickens, the results of which are presented in Table 6 .

Table 6. Biochemical parameters of the body of a daily chicken $\left(X \pm m_{x}, n=5\right)$

\begin{tabular}{|l|c|c|c|}
\hline \multirow{2}{*}{\multicolumn{1}{|c|}{ Indicator }} & \multicolumn{3}{c|}{ Group } \\
\cline { 2 - 4 } & I & II & III \\
\hline Weight of daily chicken, g & $40.80 \pm 0.37$ & $40.25 \pm 0.48$ & $40.40 \pm 0.24$ \\
\hline The contents in liver, $\mathrm{mkg} \mathrm{g}^{-1}:$ & & & \\
\hline vitamin's & $29.79 \pm 1.15$ & $34.72 \pm 2.60$ & $31.61 \pm 2.41$ \\
\hline carotene's & $39.63 \pm 5.32$ & $34.68 \pm 2.18$ & $46.16 \pm 6.36$ \\
\hline Yolk Bag Content, $\mathrm{mkg} \mathrm{g}^{-1}:$ & & & \\
\hline vitamin A & $118.62 \pm 5.90$ & $157.23 \pm 8.13^{*}$ & $148.82 \pm 11.56$ \\
\hline carotene's & $55.87 \pm 1.54$ & $41.44 \pm 3.78$ & $44.11 \pm 2.91^{* *}$ \\
\hline
\end{tabular}




\begin{tabular}{|l|c|c|c|}
\hline Contents in carca, mg: calcium & $156.58 \pm 5.91$ & $153.73 \pm 5.71$ & $141.86 \pm 0.58^{*}$ \\
\hline phosphorus's & $76.84 \pm 1.65$ & $74.55 \pm 2.50$ & $72.52 \pm 0.57^{*}$ \\
\hline other macro-and microelements & $432.48 \pm 9.05$ & $449.20 \pm 3.04$ & $407.38 \pm 6.27$ \\
\hline
\end{tabular}

The data obtained indicate that the weight of daily chickens in all groups was the same and was in the range of 40.25-40.80 g. However, in birds of experimental groups, there is a trend of higher content in the liver of vitamin A and carotene. Thus, in comparison with the I control group in II experimental group vitamin A was higher by $16.5 \%$, in the III experimental group - by $54.9 \%$, carotene in the III group - by $16.5 \%$. A similar pattern was observed in the vitamin A content in the yolk bag: in the III group the difference was $25.5 \%$, in the II experimental group - 35.2\% $(\mathrm{P} \leq 0.05)$. However, the level of carotene in the experimental groups was lower by 25.8 and $21.0 \%$. This is probably due to the development of basic internal tissues and organs of the embryo in the prenatal period of development. The decrease in calcium and phosphorus in the body of the daily embryo of the III experimental group compared with the I control group at 9.4 and $5.6 \%$ is probably due to the increased egg-laying of chickens of this group.

Accounting of egg productivity of birds of control and experimental groups and the number of fast mixed feed allowed to calculate the cost of feed per unit of produced products.

With the increase in the productivity of chickens of experimental groups, the amount of mixed fodder consumed in them was higher, and, accordingly, the metabolic energy and crude protein. However, in the I control group, $2.60 \mathrm{~kg}$ of full-scale mixed fodder, 29.36 MJ of metabolic energy and $394 \mathrm{~g}$ of crude protein were spent, in the II experimental group, the costs decreased by $8.2-8.5 \%$ on the consumption of feed and energy, $1.2 \%$ on raw protein, in the III group - by $15.0-15.4 \%$.

Similarly, feed costs per kilogram of egg-cement produced by chickens of control and test groups have changed. Thus, in the I control group, for the productive one kilogram egg mass, $4.33 \mathrm{~kg}$ of mixed fodder, $48.99 \mathrm{MJ}$ of metabolic energy and $658 \mathrm{~g}$ of crude protein were spent, in the II experimental they decreased by $1.8-9.7 \%$, in the III group - by 15.3 $15.5 \%$.

When calculating economic efficiency, it is necessary to take into account the results of growing repair young animals, as well as the cost of keeping roosters. Fed during the cultivation of the repair livestock of probiotics and during the periods of the productive cycle of laying hens led to an increase in the cost of the total cost of consumed fodder for 290 and 122 rubles, which did not affect the total cost of feed.

Gross production of eggs by poultry of control and experimental groups, as well as the preservation of livestock allowed to calculate the payment of food by products. Thus, for every $100 \mathrm{MJ}$ of feed metabolism energy fed in the second experimental group, compared with the first control group, more eggs were produced by 1.89 PCs., in the third experimental group-by 4.56 PCs., or by 8.2 and $19.7 \%$, and in value terms it was 16.32 and 36.3 PCs. eggs, or 8.5 and $18.9 \%$, respectively. However, in breeding poultry, an important indicator is the production of an incubation egg. A similar calculation showed that in absolute terms (calculated for every $100 \mathrm{MJ} \mathrm{OE} \mathrm{fed)} \mathrm{in} \mathrm{the} \mathrm{experimental} \mathrm{groups,} \mathrm{the} \mathrm{feed} \mathrm{payment} \mathrm{was}$ higher by $10.3 \%$ in the second group and $21.7 \%$ in the third experimental group, in value terms it was 10.7 and $20.9 \%$.

If the I control group produced egg products totaling 141.59 thousand rubles, the II experimental group exceeded this indicator by 18.31 thousand rubles, the III experimental group-by 27.91 thousand rubles, or by 12.9 and $19.7 \%$.

The calculation of profitability of egg production in a livestock of hens parent stock calculated by VNITIP, showed that if in the control group it was at the level of $32.4 \%$, in II it was higher by $13.1 \%$, in the III experimental group $-22.3 \%$. 


\section{Conclusions}

Periodic use of probiotic feed additives in the diet of laying hens of the parent herd allows to increase the productivity of the bird, the output, hatchability and fertilizing ability of the egg, which reduces the cost of feed per unit of production and increases the profitability of production.

\section{References}

1. P. Brandtzaeg, J. pediatr, 156, 8-15(2010)

2. A.B. Charyev, R.R. Gadiyev, Proceedings of the Orenburg state agricultural university, 6 (50), 139-141 (2014)

3. N.V. Danilevskaya, Veterinary medicine, 11, 6-10 (2005)

4. I.A. Egorov and others, World and Russian trends in the development of poultry farming: Mat. Hamidoune. Conf. World scientific organization for poultry (VNAP) Russian branch of NP Scientific center for poultry, 206-208 (Sergiev Posad, 2018)

5. A.F. Khabirov, G.R. Tsapalova, Modern problems of science and education, 4, 6 (2014)

6. A.M. Mardanova and others, World and Russian trends in the development of poultry farming: Mat. Hamidoune. Conf. World scientific organization for poultry (VNAP) Russian branch of NP Scientific center for poultry, 255-258 (Sergiev Posad, 2018)

7. N.I. Samokhina, E.A. Kapustin, N.Yu. Sadovnikova, A.V. Kuznetsov, Poultry Farming, 7, 23-26, (2017)

8. V.V. Subbotin, M.A. Sidorov, N.V. Danilevskaya, Probiotics in veterinary medicine, 11, $17-22(2000)$ 